Motrivivência $\quad$ v. 28 , n. 48 , p. $42-60$, setembro/2016

\title{
SABERES DOCENTES E FORMAÇÃO DE PROFESSORES DE EDUCAÇÃO FÍSICA: análise da Base Nacional Comum Curricular (BNCC) na perspectiva da Profissionalização do Ensino
}

\author{
Luiz Gustavo Bonatto Rufino' \\ Samuel de Souza Neto ${ }^{2}$
}

\section{RESUMO}

O presente ensaio propõe analisar o documento da Base Nacional Comum Curricular (BNCC) a partir da perspectiva da profissionalização do ensino, investigando seus desdobramentos ao âmbito da formação de professores de Educação Física. Embora o documento preconize os objetivos de aprendizagem em cada nível de ensino, sua implementação deve estar atrelada à processos de desenvolvimento profissional, alicerçados na prática. Nesse sentido, o documento não apresenta contribuições efetivas ao tema da profissionalização do ensino. Ainda, a perspectiva elaborada não leva em consideração a dimensão dos saberes docentes. A profissionalização dos professores busca desenvolver ações que possam articular políticas de valorização profissional. Há pontos importantes na BNCC que podem contribuir com a organização do campo educativo, especialmente na área da Educação Física. Contudo, é fundamental compreender a prática profissional como produtora de saberes, perspectiva que vai além da delimitação e elaboração normativa de parâmetros curriculares, vinculados aos conteúdos subjacentes às práticas corporais.

Palavras-chave: Educação Física; formação; Currículo; Docência; Profissionalização

1 Doutorando em Ciências da Motricidade. Universidade Estadual Paulista (UNESP). Rio Claro/São Paulo, Brasil. E-mail: gurufino@rc.unesp.br

2 Pós-doutorado em Educação. Professor do Departamento de Educação da Universidade Estadual Paulista (UNESP). Rio Claro/São Paulo, Brasil. E-mail: samuelsn@rc.unesp.br 


\section{INTRODUÇÃO}

Nas sociedades contemporâneas, as rápidas transformações advindas dos modos de convivência social apresentam-se para o contexto educativo como desafios bastante complexos, uma vez que a estrutura da produção de conhecimento e democratização da cultura é "posta em xeque" a todo momento (BAUMAN, 2007). Nesse contexto, a "liquidez" das relações emerge como ação dificultosa para a pedagogia, fortemente vinculada às estruturas baseadas em pressupostos tradicionais (galgados na fase "sólida" da sociedade). Porém, os mesmos devem ser revistos para que estejam de acordo com a realidade pós-moderna atual. Sendo assim, na perspectiva do sociólogo Zygmunt Bauman, considera-se que:

Os desafios do nosso tempo infligem um duro golpe à verdadeira essência da ideia de pedagogia formada nos albores da longa história da civilização: problematizam-se as "invariantes" da ideia, as características constitutivas da própria pedagogia (que, incólumes, resistiram às mudanças do passado); convicções nunca antes criticadas são agora consideradas culpadas de ter seguido o seu curso e, portanto, precisam ser substituídas (PORCHEDDU, 2009, p.662).

Hargreaves (2000), ao analisar o desenvolvimento do profissionalismo docente a partir do ponto de vista das mudanças históricas, afirma que no contexto atual, governos e sociedade devem compreender que os professores lidam com uma diversidade muito grande de alunos, em condições de incertezas éticas e morais, onde muitos métodos e abordagens são possíveis de serem implementados. O autor ainda salienta que diversos grupos sociais apresentam influência dentro da esfera educativa formal, de modo que as ações políticas para o ensino devem, inevitavelmente, compreender essa diversidade de condicionantes e, sobretudo, apresentar uma relação mais efetiva entre professores e pais (ou responsáveis) dos estudantes.

De acordo com o autor é importante considerar que nos últimos anos, tanto os investimentos do setor privado quanto as políticas públicas relacionadas ao ensino costumam exercer pressões relacionadas à intensificação do trabalho docente, ao mesmo tempo em que tendem a diminuir consideravelmente as condições e recompensas provenientes de seu exercício para esses profissionais. Hargreaves (2000) sugere que os conflitos e pressões da conjuntura relacionada à atividade laboral dos professores converge para a importância de se repensar o seu profissionalismo, bem como melhor desempenhar os processos de aprendizagem da profissão que eles precisam desenvolver para melhorar seu trabalho.

Tardif (2013), ao analisar historicamente o desenvolvimento da constituição da profissão dos professores, aponta que, por um lado, o processo de profissionalização do ensino tem procurado atingir alguns avanços importantes no que concerne, por exemplo, a busca pela autonomia e valorização profissional e construção de uma base sólida de conhecimentos que corrobore com o desenvolvimento da identidade dos professores. Todavia, por outro lado, para esse autor, esse empreendimento tem se mostrado desigual, de modo que ele não evoluiu no mesmo ritmo em todas as regiões e países, provocando tensões que inviabilizam uma reestruturação completa da profissão. Exemplos da precarização do trabalho docente podem ser arrolados, 
entre outros, pelas dificuldades e baixas condições presentes em muitas escolas públicas, a mercantilização da educação, concorrência e precarização das condições financeiras e instabilidade em serviço, interferência na autonomia do trabalho docente, entre outras.

Assim sendo, entre os aspectos abordados neste trabalho, entendemos a profissão como um método de controle do próprio trabalho (FREIDSON, 1998); por profissionalismo, ou profissionalidade, compreende-se a preocupação intrincada com a ação ocupacional e do seu caráter social, no caso da docência, a prática de ensinar (GOODSON, 2008); e por profissionalização, um "processo que transforma uma atividade desenvolvida no mundo do trabalho mediante a circunscrição de um domínio de conhecimentos e competências específicas" (WEBER, 2003, p.1127), bem como a promoção dos interesses materiais e ideias de algum grupo ocupacional (GOODSON, 2008).

Dentro do campo educativo, ao se pensar as transformações que promovam novas estruturas em consonância com as dinâmicas socioculturais atuais é fundamental compreender e analisar os processos de formação de professores - iniciais e continuados - e suas dinâmicas tendo em vista a profissionalização do ensino. Sendo assim, especial atenção recai-se para a área das políticas públicas, ao se responsabilizarem por regular, orientar, analisar, fiscalizar e alterar os pressupostos basilares dos processos pedagógicos nos níveis de ensino.

Segundo Barroso (2005), as políticas no âmbito educativo devem promover a defesa da escola pública como espaço de aquisição e distribuição equitativa de um bem comum, devendo garantir plena universalidade do acesso, igualdade de oportunidades e continuidade dos percursos escolares. Nessa visão, há o destaque para o fomento de formas mais democráticas de participação e decisão coletiva frente aos ditames políticos educacionais, fato que emerge como um dos principais desafios para o âmbito político da educação. Assim, o autor reconhece: "é certo que, em muitos casos, estes princípios não tiveram correspondência nas políticas, nas formas de organização, no currículo e nos métodos pedagógicos, em que assenta a escola de massas, ao longo da sua evolução histórica" (BARROSO, 2005, p. 746).

Em linhas gerais, podemos considerar, ainda, que em diversas situações há equívocos com relação às formas de implementação das políticas públicas no contexto educativo. Dentre os principais dilemas constata-se a visão "aplicacionista" muitas vezes presentes nesse cenário (ZEICHNER, 2013; TARDIF, 2012; PERRENOUD, 1997; PÉREZ GÓMEZ, 1995; SCHON, 1987; 1983). Nessa perspectiva, professores tendem a ser considerados apenas como "aplicadores" das teorias, normas, regulamentações e propostas de diretrizes elaboradas por especialistas, socialmente reconhecidos como conhecedores da profissão. O lugar da prática profissional é diminuído a medida que ele não é compreendido como lócus produtor de saberes.

A visão aplicacionista tem sido foco de críticas na esfera educativa. Tardif (2012), por exemplo, assinala que em boa parte das ocasiões, tanto o meio acadêmico, formado pelos estudiosos da área da educação, quanto o meio político, formado pelos envolvidos na elaboração das ações políticas para o ensino, muitas vezes compreendem os professores, que efetivamente estão nas 
ações profissionais na escola, como "aplicadores" de teorias, leis, diretrizes e regulamentações. Essa perspectiva desconsidera o trabalho docente como núcleo gerador de sentidos e significados da profissão, estando em desacordo com os processos que buscam legitimar a profissionalização do ensino.

Embora haja atualmente perspectivas que têm procurado fundamentar as propostas de desenvolvimento profissional dos professores a partir da consideração de uma base de conhecimentos alicerçada em sua prática profissional (seus saberes), é ainda comum encontrar proposições sob a ótica "aplicacionista": quer seja em termos de pesquisas científicas, ou seja no âmbito da jurisdição e das políticas públicas educativas. Tardif (2012) enfatiza que em toda atividade profissional, é imprescindível que se leve em consideração o ponto de vista dos práticos, ou seja, de quem efetivamente realiza as ações profissionais. Isso se deve porque estes profissionais são quem realmente sedimenta seu próprio trabalho e, por meio de suas experiências tanto pessoais quanto profissionais, constroem seus saberes, assimilando novos conhecimentos e competências e desenvolvendo novas práticas e estratégias de ação.

Nesse contexto, Arroyo (2001) ilustra que as divergências em termos de transformações curriculares esbarram nos interesses e diferenças de três grupos sociais distintos: os professores, que são quem efetivamente implementa a prática educativa em sua concretude, materializada diariamente durante suas aulas; os que decidem sobre os processos de inovação escolar, representados por governos e secretarias de educação e; os acadêmicos e pesquisadores que possuem na escola e no sistema educacional seu objeto de estudo. Muitas vezes esses três grupos não são condizentes entre suas ações de forma que um não contribui de maneira significativa com os anseios, necessidades e pretensões do outro, gerando inúmeras tensões.

Em muitas situações não há articulação entre cada um dos grupos (professores, pesquisadores e políticos) provocando relações hierarquizadas e pouco eficazes, ou ainda, não se dá a centralidade desse processo para os professores. Como resultado, tem-se uma desvalorização do trabalho docente como núcleo estruturante da profissão.

Para os que formulam políticas e decidem para a escola, composto pelo Estado por meio de secretarias estaduais e municipais, além do Ministério da Educação e demais órgãos competentes, a inovação curricular passa pela transformação do currículo, centrada nos conteúdos a serem ensinados. Para Arroyo (2001) essa é uma concepção reducionista de inovação, galgada na desconsideração das especificidades de cada contexto. O autor reconhece que alguns processos de inovação se apresentam de forma mais democrática, no entanto, ainda assim permanecem enraizados em perspectivas tradicionais pouco eficientes. Para ele é um erro acreditar que profundas transformações na escola básica decorrem de referenciais projetados para ela ou com ela, crença que passou a fazer parte da cultura da formulação de políticas públicas de educação que se julgam com a missão de "salvar a escola" (ARROYO, 2001).

Essa conjuntura apresenta-se como complexa, pois ao mesmo tempo em que se intensificam os investimentos da iniciativa privada no campo educativo, há a necessidade do Estado operar ações com certa 
diligência e controle. Isso se deve por conta do reconhecimento da educação como um bem público - como é o caso do Brasil - e não necessariamente como um serviço, o que também apresenta seus limites. Assim, as leis, normas e diretrizes podem ser compreendidas como importantes elementos de regulação, sendo concebidas como elementos teleológicos, uma vez que indicam uma direção e demonstram finalidades e visões de mundo a qual todo o processo educativo formal (como é o caso da educação básica) deve compor.

Margeando esse contexto político educacional mais amplo, a partir da busca pelo desenvolvimento da qualidade do ensino por meio da criação de documentos institucionais, sejam estes de cunho normativo e prescritivo, sejam propositivos ou norteadores, o Governo Federal, mais especificamente o Ministério da Educação, elaborou a Base Nacional Comum Curricular, doravante BNCC (BRASIL, 2016), cujo texto ainda está em desenvolvimento. Essa ação, juntamente com outras políticas públicas brasileiras no âmbito educacional, com destaque ao Plano Nacional de Educação, à renovação das Diretrizes Curriculares Nacionais em diversos níveis de ensino, à promulgação de programas de fomento ao ensino em diferentes áreas, entre outras, reflete um novo momento pelo qual as demandas públicas se fazem necessárias, tendo em vista as realidades contraditórias e as lacunas sociais presentes no contexto do Brasil.

De acordo com a BNCC (BRASIL, 2016), o documento tem como objetivo apresentar os direitos e objetivos de aprendizagem e desenvolvimento para cada etapa de escolarização da educação básica no Brasil. Busca-se, prioritariamente, orientar a elaboração dos currículos para todos os componentes curriculares. O documento também considera que:

\begin{abstract}
Dado seu caráter de construção participativa, espera-se que a BNCC seja balizadora do direito dos/as estudantes da Educação Básica, numa perspectiva inclusiva, de aprender e de se desenvolver. Uma base comum curricular, documento de caráter normativo, é referência para que as escolas e os sistemas de ensino elaborem seus currículos, constituindo-se instrumento de gestão pedagógica das redes. Para tal, precisa estar articulada a um conjunto de outras políticas e ações, em âmbito federal, estadual e municipal, que permitam a efetivação de princípios, metas e objetivos em torno dos quais se organiza (BRASIL, 2016, p. 25).
\end{abstract}

A BNCC (BRASIL, 2016) congrega a Educação Física como um dos componentes curriculares fundamentais em todos os níveis de escolarização da educação básica, dando a ela status, reconhecimento e legitimidade social a qual essa disciplina, historicamente, tem procurado desenvolver (BRACHT, 2001). Devido às suas tradições no currículo escolar, torna-se importante compreender como desenvolver as concepções apresentadas pela BNCC na área da formação de professores no que tange a Educação Física, analisando tanto as formas de seleção e desenvolvimento dos conteúdos propostos no documento quanto as maneiras que ele deverá ser implementado durante a prática profissional dos professores nos mais diversos e adversos contextos de intervenção social nas escolas brasileiras.

Cabe ainda destacar que frente a toda a complexa conjuntura altamente "volátil" em termos de gestão pública da política brasileira na atualidade, a investigação 
científica das formas de implementação dos documentos norteadores na esfera da educação se faz necessária, tendo em vista a construção de análises críticas que possam colaborar com o desenvolvimento do panorama sociopolítico atual. Por ser um documento ainda em elaboração, as possibilidades de investigação podem ser frutíferas e corroborar com sua implementação.

Assim, tendo em vista colaborar com o processo de análise, buscamos investigar a relação entre a BNCC (BRASIL, 2016), currículo escolar e saberes docentes na perspectiva da profissionalização do ensino, especificamente para o componente curricular Educação Física. Para isso, esse ensaio teórico, por meio da análise documental do texto da Base Nacional Comum Curricular (BNCC) em sua segunda versão, tem como objetivo analisar criticamente este documento a partir da perspectiva relacionada ao Movimento de Profissionalização do Ensino, buscando investigar seus desdobramentos ao âmbito da formação de professores de Educação Física. As análises foram divididas em três itens: 1 ) breve análise do documento da BNCC, especificamente para a área da Educação Física; 2) contextualização da perspectiva dos saberes docentes e da profissionalização do ensino e suas relações para a Educação Física e; 3) possíveis relações entre a proposta da BNCC e suas implicações para as dinâmicas de formação e desenvolvimento profissional no campo da Educação Física.

\section{Base Nacional Comum Curricular (BNCC) na área da Educação Física: saberes e conteúdos a serem desenvolvidos}

O principal mote que objetivou a criação da BNCC (BRASIL, 2016) está na orientação, organização e sistematização dos conteúdos curriculares das disciplinas escolares em cada nível de ensino, buscando parâmetros comuns a serem ensinados em todos os contextos. O fundamento básico da BNCC refere-se à aprendizagem de certos elementos da cultura como um direito de todos os estudantes. O documento busca evitar comparações com a compreensão de "currículos mínimos", os quais, por sua vez, tem sido alvo de constantes críticas e debates na área pedagógica brasileira há, pelo menos, 30 anos. Assim, o texto idealiza que parte dos conteúdos devam ser apresentados para todos os alunos e alunas enquanto que outra parte permite certa flexibilidade de acordo com cada região e contexto. É na busca de parâmetros curriculares em comuns que o documento concebe a educação como um direito social.

Para isso, o documento em diversos momentos busca justificar sua criação. Nesse sentido, é elencado o amparo legal como eixo sustentador da BNCC, justificando tanto sua elaboração, quanto sua implementação. Sendo assim, ao longo do texto, diversas leis são apresentadas. Porém, a que serve de base para esse processo é justamente a Lei de Diretrizes e Bases da Educação Nacional - LDBEN (BRASIL, 1996), a qual, em seu artigo 12, apresenta que a elaboração e execução das propostas pedagógicas por cada escola devem respeitar as normas comuns e os sistemas de ensino. Até então, apesar de haver documentos de cunho mais amplo, tais como os Parâmetros Curriculares Nacionais - PCN (BRASIL, 1998), boa parte das propostas de organização curricular estavam postas à incumbência dos Estados da federação, muitos dos quais, por sua vez, tem buscado construir e implementar uma diversidade considerável de propostas 
curriculares para os contextos sobre sua jurisdição.

Em termos de implementação de políticas públicas, o processo de elaboração da BNCC (BRASIL, 2016) pode ser considerado, em partes, até o presente momento, como diferenciado com relação aos demais documentos federais vinculados à esfera da educação até então elaborados. Tal fato se deve uma vez que permitiu, ainda que não de forma suficiente, a proposição e o debate com alguns setores da comunidade por meio de consultas públicas, reuniões institucionais, possibilidades de sugestões via plataforma eletrônica (site oficial), entre outras ações. Apesar disso, a estruturação do documento se deu por meio do convite feito à especialistas das áreas que protagonizaram a elaboração e reconstrução do texto final.

A BNCC (BRASIL, 2016) está organizada inicialmente na apresentação das justificativas de ordem legal e social para sua criação e como tem sido seu processo de desenvolvimento até o presente momento. Há também de forma pormenorizada a apresentação de cada uma das cinco áreas de conhecimento consideradas pelo documento com seus respectivos componentes curriculares: linguagens (na qual a Educação Física está vinculada), matemática, ciências da natureza, ciências humanas e ensino religioso. Ainda, o texto apresenta as etapas de escolarização da educação básica, iniciando-se pela educação infantil, passando pelo ensino fundamental (dividido entre anos iniciais e anos finais) e ensino médio. Para cada etapa são apresentados os objetivos de aprendizagem de cada um dos componentes curriculares, além de informações específicas de cada disciplina e suas relações com os níveis de ensino.
Um ponto que tem sido destacado pela BNCC (BRASIL, 2016) é a consideração dos temas especiais, assuntos de importância social que permitem estabelecer integração entre os conteúdos de cada componente curricular nas mais diversas áreas. A partir de um conjunto de leis e justificativas por meio da relevância e pertinência social, são apresentadas cinco temáticas: economia, educação financeira e sustentabilidade; culturas indígenas e africanas; culturas digitais e computação; direitos humanos e cidadania; educação ambiental. Vale ressaltar que a proposição de tais eixos apresenta bastante semelhança com o que em outros documentos foi apresentado como temas transversais (BRASIL, 1998). Contudo, apesar das explicações dentro de cada tema, não há a apresentação de proposições claras e efetivas de como articulá-los entre cada componente a partir de trabalhos interdisciplinares.

O documento da BNCC (BRASIL, 2016) reconhece que para sua efetividade ele precisa estar articulado ao conjunto de diversas ações políticas, tanto de ordem federal, quanto estadual e municipal, porém não apresenta como tais interlocuções devem ser fomentadas em cada instância. Há também certa ênfase ao caráter normativo do documento, cujo objetivo é servir de referencial para que as escolas possam elaborar seus próprios currículos, ressaltando-se que as propostas contidas em seu interior devem ser desenvolvidas, embora há o reconhecimento das dificuldades existentes acerca da pluralidade e diversidade de contextos presentes no país.

Especificamente nas partes do documento destinadas à Educação Física, cabe ressaltar que a BNCC (BRASIL, 2016), tais como em outras normas, parâmetros e 
diretrizes anteriores, é considerada dentro da área de "Linguagens", a qual, por sua vez, é entendida de maneira mais ampla, sendo considerada como a forma como são desenvolvidas as relações pessoais e institucionais e a participação na vida em sociedade. Se, por um lado, tal alocação da Educação Física nessa área é alvo de críticas, por outro lado entende-se que o texto mantém coerência com proposições anteriores que tem vinculado este componente na área das linguagens em diversos momentos (a exemplo dos Parâmetros Curriculares Nacionais para o Ensino Médio, Orientações Curriculares Nacionais, Parâmetros Curriculares Mais (PCN +), entre outros.

A BNCC (BRASIL, 2016) compreende a Educação Física como um componente curricular de suma importância ao possibilitar às novas gerações a preservação e a reconstrução crítica de toda a herança cultural acumulada historicamente pela humanidade, a partir de conhecimentos sistematizados. Tem-se o esforço de alinhar os pressupostos pedagógicos desse componente curricular aos propósitos republicanos que regem a educação básica brasileira.

Nessa perspectiva, é responsabilidade da Educação Física tratar das práticas corporais em suas diversas formas de codificação e significação social, entendidas como manifestações das possibilidades expressivas dos sujeitos, por meio da gestualidade e do patrimônio cultural da humanidade, produzidas por diversos grupos sociais no decorrer da história. Nas aulas, tais práticas devem ser abordadas como um fenômeno cultural dinâmico, diversificado, pluridimensional, singular e contraditório, assegurando a construção e a reconstrução de um conjunto de conhecimentos necessários à formação do cidadão, que permitam a participação dos/as estudantes de forma confiante e autoral na sociedade, bem como a ampliação dos recursos para o cuidado de si e dos outros (BRASIL, 20016, p. 99).

Tais como em documentos antecessores, a BNCC (BRASIL, 2016) reforça a concepção da Educação Física vinculada às práticas corporais, denominadas de manifestações da cultura corporal de movimento, valorizando a democratização e o acesso a esse conjunto de práticas, bem como o desenvolvimento de sentidos e significados dos alunos para com elas. Para isso, é sugerido a diversificação de conteúdos, além de sua sistematização para cada nível de ensino.

O texto da BNCC (BRASIL, 2016) abrange uma breve retrospectiva histórica da Educação Física na escola, partindo da concepção que a vincula como mera atividade até sua ressignificação à componente curricular obrigatório, garantido por lei. Para isso, há a contextualização do movimento renovador da área a partir da década de 1980. Apresenta-se também um aporte de leis e documentos os quais buscaram reforçar o entendimento da importância da Educação Física na escola (LDB, PCN, etc.). De maneira didática, são elencados quatro grandes conjuntos de desafios para a valorização dessa disciplina na escola, cada qual com seus respectivos desdobramentos: desafios de legitimação ético-política, desafios curriculares, desafios interdisciplinares e desafios didáticos. De forma geral, reconhece-se tanto a importância de formulação de sentidos para a Educação Física escolar, quanto a necessidade de organização dos conhecimentos que este componente curricular é responsável. Além disso, é fundamental para o documento fomentar o 
diálogo com os conhecimentos produzidos pelas demais áreas e, finalmente, elaborar estratégias para o ensino e avaliação dessa disciplina.

Ao caracterizar a tematização das práticas corporais na escola, o documento compreende três elementos fundamentais: o fato delas apresentarem como elemento essencial o movimento humano, possuírem uma organização interna baseada em uma lógica específica de ação e serem produtos culturais ligados ao lazer e/ou ao cuidado com o corpo e a saúde (BRASIL, 2016). Percebe-se claramente a influência de algumas áreas na construção das perspectivas sobre as práticas corporais, vinculadas, por exemplo, às novas perspectivas oriundas da pedagogia do esporte, de estudos do lazer e também da praxiologia motriz. A partir desse embasamento são elencadas as manifestações da cultura corporal de movimento preconizadas pelo documento: brincadeiras e jogos, danças, esportes, ginásticas (demonstração, condicionamento físico e conscientização corporal), lutas e práticas corporais de aventura. Toda a organização didática apresentada nos objetivos de aprendizagem ramifica-se dessas manifestações corporais.

Com relação à sistematização curricular, no caso da Educação Física, a BNCC (BRASIL, 2016) está organizada por meio de "ciclos de escolaridade", sendo dois para os anos iniciais do ensino fundamental (um para o $1^{\circ}, 2^{\circ}$ e $3^{\circ}$ anos e outro para o $4^{\circ}$ e $5^{\circ}$ anos), dois para os anos finais do ensino fundamental (um para o $6^{\circ}$ e $7^{\circ}$ anos e outro para o $8^{\circ}$ e $9^{\circ}$ anos) e um para o ensino médio $\left(1^{\circ}, 2^{\circ}\right.$ e $3^{\circ}$ anos). De acordo com o documento, essa escolha se faz importante para que haja certa flexibilidade no desenvolvimento dos conteúdos dentro de cada ciclo. De acordo com o texto em sua segunda versão:

(...) os objetivos apontados como base curricular indicam que o/a estudante tem direito a aprender determinados conhecimentos em cada etapa. Isso não impede que os projetos escolares do componente antecipem, ou aprofundem, posteriormente, as aprendizagens previstas para determinada fase. Apenas está sendo sinalizada a necessidade de que esses conhecimentos sejam efetivamente trabalhados até o final do ciclo indicado (BRASIL, 2016, p. 107).

Há ainda a indicação do que o manuscrito denominou de "dimensões do conhecimento", que são conceitos e diretrizes que devem ser abordados durante a prática pedagógica e que permitem a tematização das práticas como saberes escolares. Sendo assim, são elencados oito elementos: experimentação, uso e apropriação, reflexão sobre a ação, construção de valores, análise, compreensão e protagonismo comunitário (BRASIL, 2016). Em seu conjunto, tais aspectos são abordados tendo em vista valorizar e favorecer a vivência das atividades corporais, bem como a reflexão crítica sobre elas e também sobre os potenciais valores e condutas éticas delas desenvolvidos, ou seja, valorizam a dimensão do saber proveniente das práticas corporais, bem como do fazer/ realizar e do conjunto de valores possíveis de serem abordados. Embora reconheça-se a importância de cada dimensão para a prática profissional dos professores de Educação Física, no texto não é proposto formas efetivas e possibilidades concretas de relação entre elas ao longo da prática pedagógica, o que poderá dificultar as formas com que os docentes poderão desenvolvê-las durante seu trabalho. Assinala-se ainda 
que tais aspectos apresentam semelhança com as "dimensões dos conteúdos" (conceitual, procedimental e atitudinal), a qual outros documentos anteriores são baseados, embora não haja no texto qualquer alusão a respeito dessa possível relação.

Na parte mais específica da BNCC na Educação Física são apresentados os objetivos de aprendizagem para cada ciclo de escolaridade. Podemos considerar tais ações como o "carro chefe" do documento uma vez serem eles os elementos que nortearam o desenvolvimento do currículo, assegurando o que deve ser abordado durante a prática pedagógica. No total de todos os ciclos, são apresentados quase 250 objetivos de aprendizagem, abarcando todos os conteúdos, ciclos e manifestações da cultura corporal elegidas pelo documento. Desses objetivos, destaca-se grande complexidade no tratamento pedagógico de alguns, o que muitas vezes pode não coadunar com os problemas de ordem de formação de professores encontrado no momento no Brasil e gerar dificuldades de abordagem durante as aulas de Educação Física. Nesse ponto, a perspectiva do desenvolvimento da formação docente ganha força para que o documento possa apresentar um impacto efetivo dentro do que ele propõe.

Finalmente, destaca-se que a tônica do documento da BNCC (BRASIL, 2016) na área da Educação Física é a diversificação das práticas corporais, mas com preocupações de que se possam atingir objetivos concretos de aprendizagem, valorizando regionalidades, e considerando aspectos vinculados às pessoas com deficiência e alguns momentos do texto. Nesse sentido, a BNCC salienta que as práticas selecionadas dentro de cada contexto (exemplo, na comunidade escolar específica) devem ser aprendidas com maior nível de proficiência. Por outro lado, as práticas tematizadas na perspectiva de experimentar privilegiam a diversidade de conteúdos e a vivência por meio da ampliação das oportunidades de prática. Tem-se assim certa flexibilidade e a possibilidade de diversificação de parte dos conteúdos, bem como de aprofundamento de outros tantos.

\section{Saberes docentes e profissionalização do ensino: elementos para se pensar a docên- cia no século XXI}

A prática educativa é muito complexa. Nela estão contidos diversos elementos representados, como aponta Schön (1983), por situações de incerteza, instabilidade, singularidade e conflito de valores. Para compreender a prática dos professores, mais do que proposições legais, reflexões teóricas aprofundadas e hierarquizações que compõem os sistemas educacionais, é preciso valorizar o que de fato os profissionais fazem, ou seja, compreender a docência como um trabalho e o professor como um trabalhador profissional.

No entanto, historicamente, a análise sobre o ensino ilustra que muitas vezes ele foi concebido como uma atividade no qual qualquer pessoa era capaz de exercer, desde que tivesse um mínimo domínio de conhecimentos para serem ensinados. Com efeito, durante muito tempo, ser professor não era compreendido como um trabalho reconhecido, de forma que frases do tipo: "mas você trabalha ou só dá aulas?", ainda podem ser encontradas no senso comum. Foi preciso um intenso movimento que buscasse questionar tais compreensões equivocadas e valorizasse o trabalho docente e 
a emergência de uma cultura profissional. Essa perspectiva é denominada de profissionalização do ensino.

De acordo com Tardif (2013), embora a profissionalização do ensino represente uma tendência no ocidente ao longo do século XX, ela foi intensificada a partir da década de 1980, por meio de um conjunto de ações oriundas de diversos países. Entre outras, destaca-se, por exemplo, a criação do relatório redigido por decanos de importantes universidades norte-americanas que ficaram conhecidos como "Holmes Group" (1986). Esse documento, considerado um marco para o movimento de profissionalização do ensino, explicitava, entre outras coisas, a necessidade da criação de formas de melhorar os programas de formação de professores, sendo necessário o desenvolvimento de um amplo conjunto de conhecimentos compatível com as necessidades que a profissão docente apresentava.

Tardif (2013) salienta que o movimento de profissionalização do ensino apresentou um triplo objetivo: melhorar o desempenho do sistema educativo, passar do ofício à profissão e construir uma base de conhecimentos sólida para o ensino. Para esse autor, apesar de avanços terem sido encontrados, o desenvolvimento da profissionalização não tem sido apresentado de forma linear, de modo que as políticas atuais apresentam uma estagnação e até mesmo uma retração em sua transformação de ofício à profissão.

Apesar das inúmeras incongruências que deslegitimam o ensino enquanto profissão, o cenário das discussões atuais indica que, a despeito das diversas dificuldades existentes, sua profissionalização pode ser considerada como uma possibilidade importante de desenvolvimento do cenário educativo atual. Gauthier et al. (2013) destacam que, embora possam haver problemas decorrentes desse processo que precisam ser considerados, a profissionalização do trabalho dos professores é um projeto de ação muito promissor.

Entre os inúmeros avanços que a profissionalização do ensino poderia trazer, com destaque para a valorização profissional, maior reconhecimento financeiro, melhora nas condições de trabalho, desenvolvimento da autonomia de trabalho, entre outros, a consolidação de um conjunto de conhecimentos considerados como base para o ensino é um dos mais importantes. Isso se deve uma vez que uma profissão reconhecida precisa apresentar um corpo de conhecimentos e saberes que a legitime e a diferencie das demais. Nesse sentido, o relatório apresentado pelo "Holmes Group" já apontava que os professores carecem de saberes profissionais fundamentais (HOLMES GROUP, 1986). Gauthier et al. (2013), por sua vez, afirmam que a definição de um corpus de saberes válidos para a prática profissional dos professores, além de permitir a profissionalização do ensino, é importante pois possibilita uma melhor orientação daqueles que a exercerão, ou seja, apresenta implicações fundamentais para a formação de professores.

Para Gauthier et al. (2013), a determinação desse repertório específico de conhecimentos deve ser feita a partir da análise do trabalho docente. De acordo com os autores é preciso superar as visões que relacionam o ensino tanto como um "ofício sem saberes" (galgado na reprodução por tentativa erro), quanto como de "saberes sem ofício" (fundado no aplicacionismo das ciências da educação). Para isso, é preciso compreendê-lo como um "ofício feito de 
saberes", valorizando o trabalho dos professores como núcleo gerador de sentidos de sua profissão.

Sendo assim, de acordo com Gauthier et al. (2013), embora muitas pesquisas de diferentes vertentes têm sido realizadas com relação aos conhecimentos de base para o ensino, a determinação desse repertório específico deve ser feita a partir da análise do trabalho docente. Ora, uma vez que este repertório de saberes é utilizado na prática pelos professores, as análises devem ser realizadas a partir do que os docentes realmente fazem ao longo de suas ações profissionais (TARDIF, 2012), ou seja, é preciso desvelar os seus saberes.

Emerge, desse contexto, a compreensão de saberes docentes, entendidos como uma possibilidade de representação dos conhecimentos de base para a profissão dos professores. Tardif (2012) compreende os saberes em um sentido amplo, no qual estão representados os conhecimentos, as práticas, as competências e as habilidades necessárias para o exercício profissional da docência. Busca-se assim superar a visão de que para ensinar é preciso apenas de conhecimentos científicos. De acordo com o autor, os saberes podem ser considerados como "formado pelo amálgama, mais ou menos, coerente, de saberes oriundos da formação profissional e de saberes disciplinares, curriculares e experienciais" (TARDIF, 2012, p. 36).

Gauthier et al. (2013) apresentam a mesma tipologia dos saberes, ampliando-a, bem como ressignificando alguns aspectos, como: saberes disciplinares, produzidos pelos pesquisadores e cientistas das disciplinas acadêmicas; saberes curriculares, vinculados aos programas de ensino, currículos, propostas pedagógicas, diretrizes institucionais, livros didáticos, entre outros; saberes das ciências da educação, os quais permeiam a maneira do professor existir profissionalmente, vinculando-se às correntes científicas e orientações teóricas; saberes da tradição pedagógica, relacionados à tradição histórica do que é ensinar, passado a cada geração de forma empírica; saberes experienciais, os quais se referem às experiências pessoais de cada professor e como eles as ressignificam cotidianamente no exercício de seu trabalho; saberes da ação pedagógica, vinculados às formas de tornar público os saberes da experiência, por meio de cursos, falas, rodas de conversa, etc.

Em suma, a compreensão dos saberes docentes permite uma maior apropriação das relações encontradas durante a prática profissional. Entretanto, se na prática, como apontou Schön (1983), emergem uma série de problemas cujas respostas precisam ser oferecidas no momento em que acontecem e que, na grande maioria das vezes, fogem aos pressupostos científicos, os saberes docentes permitem compreender a fonte desse conjunto de ações, valorizando, sobremaneira, o trabalho dos professores.

Para isso, é necessário outro tipo de racionalidade, uma vez que a racionalidade técnica, baseada no "aplicacionismo" de teorias não considera os professores como produtores de saberes apenas como aplicadores dos ditames e postulados científicos. A perspectiva dos saberes docentes, por sua vez, compreende que a prática profissional é lugar de mobilização de um conjunto de saberes provenientes de diferentes fontes os quais produzem e geram novos conhecimentos. Dessa forma, ao pensar a docência nos dias de hoje deve-se valorizar os contextos de prática profissional dos professores, compreendendo as fontes 
que geram os saberes profissionais, bem como é fundamental repensar a formação de professores, para que ela seja mais adequada no que se refere à valorização da profissão docente.

\section{A BNCC na perspectiva da profissionali- zação do ensino: limites e possibilidades}

Ao se implementar uma política pública educativa, é muito frequente que, em algum momento, parte das soluções e também parte dos problemas sejam alocados para a formação de professores. Isso se deve porque, em suma, a formação profissional quando superficialmente analisada, tende a ser compreendida como a "salvadora" de todos os problemas, ou então, a "causadora" de todos os males que impedem o desenvolvimento efetivo de tal ação política. Ambas as perspectivas, além de simplórias e desarticuladas, impedem que se estabeleça uma relação efetiva entre processos formativos alicerçados na prática profissional e políticas públicas claramente elaboradas levando-se em consideração a valorização do trabalho docente. Para que uma determinada proposta tenha impacto efetivo na prática profissional, compreender criticamente os processos formativos é condição prioritária, sem a qual corre-se o risco de que as proposições fiquem apenas no âmbito institucionalizado e não cheguem a ser colocadas efetivamente à cabo durante a prática pedagógica.

Nesse sentido, considera-se que a análise proveniente do documento da BNCC (BRASIL, 2016) não demonstra claramente em nenhum momento como deve estar articulada a dimensão política da dimensão formativa. Assim, perde-se uma grande oportunidade de construção coletiva das relações entre as perspectivas que delimitam os conteúdos de aprendizagem com as formas com que os currículos devem ser compreendidos pelas instâncias formativas, inserindo-se nesse contexto tanto a formação inicial para os futuros profissionais que iniciarão o exercício profissional já sob orientação da BNCC, quanto a formação continuada, abrangendo os inúmeros docentes que estejam em atuação profissional e terão que compreender esse novo paradigma de trabalho. A efetividade da implementação dessa política é diretamente proporcional à sua responsabilidade no que corresponde a formas efetivas de estabelecer diálogos coerentes com o âmbito da formação de professores no Brasil.

A exceção feita refere-se ao quadro apresentado na página 26 do documento (BRASIL, 2016), o qual ilustra em termos políticos o "lugar" da BNCC advindo de um desdobramento da Constituição Federal, LDB, Política Curricular Nacional e Diretrizes Curriculares. Da BNCC saem alguns eixos norteadores, superficialmente abordados no documento: Política Nacional de Formação de Professores; Política Nacional de Materiais e Tecnologias Educacionais; Política Nacional de Infraestrutura escolar; Política Nacional de Avaliação da Educação Básica. O documento não explica de que maneira deve-se articular a BNCC com as políticas nacionais de formação docente, indicando uma lacuna entre o que é proposto e sua implementação.

Cabe ressaltar que a Política Nacional de Formação de Professores está enquadrada dentro do Plano Nacional de Formação dos Professores da Educação Básica, bem como ambos compõem o Sistema Nacional de Formação de Professores. Em 
linhas gerais, essas proposições de caráter político e institucional buscam priorizar ações que desenvolvam e estimulem a integração dos cursos e processos de formação iniciais e continuados, buscando sedimentar novos meios de ampliação do número de professores no Brasil, bem como intensificando a qualidade dos profissionais em exercício. Propõem-se, assim, saltos qualitativos e quantitativos no que corresponde a formação para o trabalho docente no Brasil. Todavia, não há clareza entre as formas com que a BNCC pode contribuir efetivamente para tal intento. O documento deve então, possivelmente em versões reformuladas do mesmo, apresentar esse panorama de forma mais clara e explícita, sem o qual pouco se pode compreender sobre sua efetividade no que corresponde ao eixo formação.

Em se tratando da análise da BNCC (BRASIL, 2016) é preciso considerar que no âmbito da educação no Brasil, há certo "temor" apresentado por algumas correntes teóricas com relação ao estabelecimento de um conjunto de conhecimentos padrão para diversas realidades e contextos. Esse procedimento, fortemente criticado no passado, tende, na visão de algumas abordagens teóricas, a "engessar" os saberes que compõem o currículo e podem descontextualizar os processos de ensino e aprendizagem e de socialização ao desconsiderarem as múltiplas realidades e diversidade de contextos existentes. Mesmo sendo afirmado em diversos pontos do documento a importância de se considerar as especificidades de cada contexto de prática, essa política pública apresenta claramente a visão que considera que alguns conteúdos curriculares devem ser abordados independente da região, o que não deve ser visto como uma forma de desvalorizar os saberes locais, mas de garantir a universalidade de determinados elementos da cultura. No caso da Educação Física, por sua história fortemente vinculada ao ensino de apenas alguns conteúdos, essa diversificação e consideração de objetivos de aprendizagens baseados em diversas manifestações corporais pode ser visto como um avanço, desde que devidamente compreendido na prática.

Em termos de análise da efetividade na implementação da BNCC (BRASIL, 2016) é preciso considerar diversos fatores condicionantes que podem favorecer ou prejudicar o seu desenvolvimento. No entanto, a partir da perspectiva apresentada pelos saberes docentes, tendo como foco a construção de uma base de conhecimento para o ensino (knowledge base), podemos considerar que, em linhas gerais, o documento da BNCC apresenta direcionamentos que podem vir a impactar de certa forma e de modo mais específico um conjunto de saberes vinculados aos saberes curriculares, relacionados aos programas de ensino, currículos, diretrizes curriculares, propostas pedagógicas, parâmetros curriculares, livros didáticos, entre outros (GAUTHIER et al., 2013). Os saberes curriculares abrangem tradições pedagógicas e estão fortemente atrelados às orientações curriculares e aos processos de organização e sistematização dos conteúdos escolares que, por sua vez, tendem a desenvolver, direcionar e orientar o trabalho docente.

Embora a área da educação ainda careça de estudos que analisem criticamente o impacto efetivo desse conjunto de saberes de origem curricular durante a prática pedagógica, estudos tem apontado que, por se tratar de uma amálgama complexa e subjetiva, outros saberes têm sido considerados como mais preponderantes 
em termos de efetividade prática, com destaque aos saberes da experiência (TARDIF, 2012). Nesse sentido, é possível inferir que a efetividade da BNCC (BRASIL, 2016) está fortemente relacionada à sua capacidade de mobilizar e desenvolver um conjunto maior de saberes, o que deveria ser fomentado por meio de outras iniciativas para além da definição dos objetivos de aprendizagem em cada componente curricular.

Dessa forma, a partir da perspectiva teórica apresentada, torna-se uma tarefa um tanto quanto perigosa avaliar a efetividade do documento da BNCC (BRASIL, 2016) para a prática pedagógica, uma vez que o documento se limita a propor orientações cujo direcionamento induz, em princípio, a abrangência de apenas parte da complexidade dos saberes docentes - os saberes curriculares. Outros saberes poderão ser mobilizados em decorrência de sua implementação, porém, para isso, mais estudos e pesquisas são necessários, os quais devem compreender os contextos práticos de atuação dos professores. Como salienta Tardif (2012, p. 234), o trabalho docente "deve ser considerado como um espaço prático específico de produção, de transformação e de mobilização de saberes e, portanto, de teorias, de conhecimentos e de saber-fazer específicos ao ofício de professor".

Caso a proposta de elaboração e implementação da BNCC (BRASIL, 2016) esteja articulada com ações efetivas que possam mobilizar um amplo espaço de discussão e ressignificação dos saberes em suas mais diversas dimensões, é possível inferir que seu impacto tende a ser mais efetivo. Assim, tendo em vista a formação de professores, seja ela inicial ou continuada, suas implicações se tornariam dinamizadas em estruturas formativas mais críticas e articuladas com o trabalho real dos professores. Por outro lado, a medida que este documento seja compreendido como mais uma ação legal e normativa cujas relações com a prática tornam-se muito afastadas, sua efetividade tenderá a ser menor e, consequentemente, propiciará menos impacto para o desenvolvimento do trabalho dos professores de Educação Física.

No que diz respeito a BNCC (BRASIL, 2016) é possível entendê-la como um descritor de conteúdos e saberes necessários para cada ano e segmento da Educação Básica. O que se busca é um currículo nacional no qual se garanta no processo de escolarização dos alunos conteúdos essenciais ao desenvolvimento educacional do país, tendo em vista a equidade do ensino, o respeito a realidade local, bem como o cumprimento da meta 7 do Plano Nacional de Educação (PNE): fomentar a qualidade da Educação Básica, do fluxo escolar e da aprendizagem. De modo que se os PCN (BRASIL, 1998) se caracterizavam mais como sugestões ou subsídios de conteúdos, não explicitando o que o professor tem de ensinar ou como os alunos devem aprender, a BNCC, enquanto diretriz, parte de uma perspectiva de que o professor deveria ter uma formação que o capacitasse para adapta-la a sua realidade, tendo como compromisso que os conteúdos essenciais deveriam ser ensinados. Face a esta perspectiva, é possível que aconteça mudanças tanto no âmbito dos conteúdos quanto na questão da formação inicial e continuada, bem como na própria profissionalização do ensino, fazendo uma relação entre a formação inicial e a formação continua.

A partir dos objetivos de aprendizagem apresentados pela BNCC (BRASIL, 2016) na Educação Física, fica claro que é 
preciso repensar a formação inicial e continuada dos professores. Isso se deve uma vez que boa parte das proposições apresentam um caráter inovador, a exemplo da forma de apresentação dos conteúdos esportivos, baseados em novas perspectivas técnico-táticas, que dialoga com um conjunto de conhecimentos muitas vezes distantes da grande maioria dos processos formativos atuais.

Sendo assim, da mesma forma que as possíveis inconsistências advindas dos cursos de formação em Educação Física no Brasil não devem ser utilizados como justificativa para o não domínio dos conteúdos de aprendizagem preconizados pela base nacional, por outro lado, não se deve almejar que a formação a partir de agora deva estar subordinada aos ditames preconizados por este documento. A BNCC (BRASIL, 2016) não se trata de um artefato tal como a "Caixa de Pandora", ao mesmo tempo em que traz um novo panorama o qual precisa ser analisado criticamente. $\mathrm{O}$ fomento de estudos e pesquisas no âmbito da formação docente na Educação Física torna-se fundamental e poderá auxiliar na análise desses novos contextos emergentes.

\section{CONSIDERAÇÕES FINAIS: OS DESAFIOS E AS POSSÍVEIS CONTRIBUIÇÕES DA BNCC PARA A FORMAÇÃO DE PROFES- SORES DE EDUCAÇÃO FÍSICA}

No presente ensaio buscou-se fazer uma análise documental da BNCC (BRASIL, 2016), tendo como foco de orientação a profissionalização do ensino. Não se deixa de reconhecer que a referida proposta está fortemente atrelada à formação para a cidadania, assim como ela procura sedimentar uma base de conhecimento que pode fundamentar a Educação Física na escola e sua possibilidade de integração com outros conteúdos. O fato dela não apresentar uma orientação metodológica restrita e específica também pode ser compreendido como um avanço, pois permite ao professor e a escola fazerem as suas escolhas didáticas sem engessar o processo.

No entanto, nos chama a atenção a importância de considerarmos o complexo processo: professor - profissão - escola conteúdo. De acordo com Nóvoa (1995) é preciso repensar o desenvolvimento pessoal (produzir a vida do professor), o desenvolvimento profissional (produzir a profissão docente) e o desenvolvimento organizacional (produzir a escola). No caso da Educação Física na escola, esta disciplina tem sido marcada no atual momento pelo desenvolvimento disciplinar (produzir a disciplina Educação Física). Esse fato demonstra que este componente curricular ainda está em processo de busca por sua legitimidade social dentro do contexto escolar.

Não se deixa de reconhecer a evolução da Educação Física escolar concebida como "atividade", nas Diretrizes Curriculares de Educação Física para a Escola com o Decreto-Lei 69450/71, para "componente curricular" na LDBEN 9394/96 (BRASIL, 1996). Porém, ela tem relegado a segundo plano a articulação desse conteúdo com a questão da formação de professores, exercício da profissionalidade docente e a aquisição de uma cultura profissional (profissão docente), por conta da busca de legitimidade como disciplina no seio da escola e das políticas públicas. Embora seja um fato no presente superado, seu desenvolvimento disciplinar ainda continua sendo a tônica de suas ações na esfera política. 
Entretanto, também se infere que as proposições contidas na BNCC (BRASIL, 2016) tem como intenção chegar às universidades, assim como servir de referência nas avaliações de curso e de professores. Dentro desse contexto chamamos atenção para outros desafios. De forma didática, apresentamos três cenários possíveis:

1) No primeiro cenário, a BNCC passa a ser um documento amplo e reconhecido, ao menos em grande parte do país, o que exige uma intensa discussão sobre a formação de professores de forma que possa compreender integralmente as possibilidades e desdobramentos do documento. Nesse sentido, corre-se um duplo risco:

a) Desenvolver uma perspectiva "utilitarista" para a formação de professores, sendo esta uma forma de suprir os conteúdos específicos deste material, ou seja, forma-se para a BNCC, do mesmo modo que este documento se torna a base da formação profissional;

b) Desenvolver uma perspectiva de formação como "salvadora" dos infortúnios e dilemas advindos da prática profissional, ou seja, a formação, novamente passa a ser a "panaceia" para a resolução de todos os problemas do ensino. Essa perspectiva é perigosa à medida que todas as dificuldades e deficiências possíveis de haver no documento passam a ser consideradas não como um problema da política em si e nem do documento, mas da formação, como se esta fosse algo "externo".

2) No segundo cenário, a BNCC passa a ser considerada apenas mais uma proposta cujo "impacto" para a prática é ineficiente e menor do que deveria ser enquanto política pública. Nessa perspectiva, este será mais um documento a ocupar o espaço nas estantes das escolas, sem viabilizar mudanças efetivas e nem conseguir atingir aos objetivos propostos.

3) O terceiro cenário, talvez o mais utópico dos três, indica a compreensão da BNCC como "UM" dos elementos que compõe apenas uma parte da complexidade de saberes mobilizados no ato de ensino. Sendo assim, ela pode contribuir com a formação docente à medida que dialoga com a prática profissional, busca desenvolver formas de valorizar o trabalho docente e permite introduzir uma nova cultura de aprendizagem e desenvolvimento da profissão de professor de Educação Física, fortemente vinculada às dinâmicas da prática pedagógica.

Concluiu-se que há pontos importantes na BNCC (BRASIL, 2016) que podem contribuir com a organização do campo educativo, especialmente na área da Educação Física. Contudo, é fundamental também compreender a prática profissional como produtora de saberes, perspectiva que vai além da delimitação e elaboração normativa de subsídios curriculares, vinculados aos conteúdos subjacentes às práticas corporais.

\section{REFERÊNCIAS}

ARROYO, M. G. Experiências de inovação educativa: o currículo na prática da escola. In: MOREIRA, A. F. B. (Org.). Currículo: políticas e práticas. Campinas: Papirus, 2001.

BARROSO, J. O Estado, a Educação e a regulação das políticas públicas. Educação e Sociedade, v. 26, n. 92, p. 725-751, out. 2005.

BAUMAN, Z. Vida líquida. Rio de Janeiro: Jorge Zahar, 2007.

BRACHT, V. Saber e fazer pedagógicos: acerca da legitimidade da Educação 
Física como componente curricular. In: CAPARROZ, F. E. Educação Física escolar: política, investigação e intervenção. Vitória: PROTEORIA, 2001, p. 67-79.

BRASIL, Ministério da Educação. Base

Nacional Comum Curricular. Proposta

Preliminar. Segunda Versão - Revista.

Brasília: Secretaria da Educação Básica, 2016.

BRASIL, Ministério da Educação e do Desporto. Lei de Diretrizes e Bases da Educação Nacional. Brasília: MEC, 1996. Disponível em<http://www. planalto.gov.br/ccivil_03/LEIS/I9394. htm > . Acesso em: 20 maio 2016.

BRASIL. Ministério da Educação e do Desporto. Secretaria de Educação Fundamental. Parâmetros Curriculares Nacionais: Educação Física, 3o e 4o ciclos. Brasília, 1998. v.7.b.

FREIDSON, E. O renascimento do profissionalismo. São Paulo: EDUSP, 1998.

GAUTHIER, C.; MARTINEAU, S.; DESBIENS, J. F.; MALO, A.; SIMARD,

D. Por uma Teoria da Pedagogia:

Pesquisas Contemporâneas sobre o Saber Docente. Ijuí: Unijuí, 2013.

GOODSON, I. F. Conhecimento e Vida

Profissional: estudos sobre educação e mudança. Porto: Porto Editora, 2008.

HARGREAVES, A. Four Ages of Professionalism and Professional Learning. Teachers and Teaching: History and Practice, v. 6, n. 2, p. 151182, 2000.

HOLMES GROUP. Tomorrow's Teachers:

a Report of the Holmes Group. East Lansing, MI: Holmes Group, 1986.

NÓVOA, A. Formação de professores e profissão docente. In: NÓVOA, A.
(Org.). Os professores e a sua formação. 2. ed. Lisboa: Dom Quixote, 1995. p.15-33.

PÉREZ GÓMEZ, A. I. O pensamento prático do professor - a formação do professor como profissional reflexivo. In: NÓVOA, A. Os professores e sua formação. $2^{\mathrm{a}}$ ed. Lisboa: Dom Quixote, 1995.

PERRENOUD, P. Práticas pedagógicas, profissão docente e formação: perspectivas sociológicas. Lisboa: Dom Quixote, 1997.

PORCHEDDU, A. Zygmunt Bauman: entrevista sobre a educação. Desafios pedagógicos e modernidade líquida. Cadernos de Pesquisa, v. 39, n. 137, p. 661-684, maio/ago. 2009.

SCHÖN, D. A. The reflective practitioner: how professionals think in action. USA: Basic Books, 1983.

SCHÖN, D. A. Educating the reflective practitioner: toward a new design for the teaching and learning in the professions. San Fracisco: Jossey-Bass, 1987.

TARDIF, M. A profissionalização do ensino passado trinta anos: dois passos para a frente, três para trás. Educação e Sociedade, v. 34, n. 123, p. 551-571, 2013.

TARDIF, M. Saberes docentes e formação profissional. Petrópolis: Vozes, 2012.

WEBER, S. Profissionalização docente e políticas públicas no Brasil. Educação e Sociedade, v. 24, n. 85, p. 1125-1154, dez. 2003.

ZEICHNER, K. M. Políticas de formação de professores nos Estados Unidos: Como e por que elas afetam vários países no mundo. Belo Horizonte: Editora Autêntica, 2013. 
TEACHERS' KNOWLEDGE AND PHYSICAL EDUCATION TEACHER EDUCATION: ANALYSIS OF "BASE NACIONAL COMUM CURRICULAR" (COMMON CURRICULAR NATIONAL STANDARDS) IN THE PERSPECTIVE OF TEACHERS PROFESSIONALIZATION

\begin{abstract}
The presented essay search to analyze the "Common Curricular National Standards" Brazilian document (Base Nacional Comum Curricular), in the view of teaching professionalization, investigating its consequences to the field of Physical Education Teacher Education (PETE). Although the document advocate learning goals at each level of education, its implementation should be linked to professional development processes, grounded in the field of practice. In this sense, the document does not present effective contributions to the theme of teaching professionalization. In addition, the elaborate perspective does not take into account the dimensions of teachers' knowledge. Teachers' professionalization seeks to develop actions that can articulate professional development policies. There are important points in BNCC that can contribute to the organization of educational field, especially in the area of Physical Education. However, it is very important to understand the professional practice as a producer of knowledge, perspective that goes beyond the boundaries and rules elaboration of curriculum guidelines, linked to the underlying content of bodily practices.
\end{abstract}

Keywords: Physical Education; formation; Curriculum; Teaching; Professionalization

CONOCIMIENTO DE LOS PROFESORES Y LA FORMACIÓN DOCENTE EN LA EDUCACIÓN FÍSICA: ANÁLISIS DE LA "BASE NACIONAL COMUM CURRICULAR" (BASE NACIONAL COMÚN CURRICULUM) EN LA PERSPECTIVA DE PROFESIONALIZACIÓN DE LA ENSEÑANZA

\title{
RESUMÉN
}

Este ensayo tiene como objetivo analizar el documento "Base Nacional Común Curriculum" en la perspectiva de la profesionalización de la enseñanza y la investigación de sus consecuencias en el campo de la Formación de los Profesores de Educación Física. Aunque el documento debería defender los objetivos de aprendizaje en cada nivel de educación, su aplicación debe estar vinculada a los procesos de desarrollo profesional, basadas en la práctica. En este sentido, el documento no presenta contribuciones efectivas al tema de la profesionalización docente. Además, la perspectiva elaborada no tiene en cuenta las dimensiones del conocimiento de los profesores. La profesionalización de los maestros busca desarrollar acciones que puedan articular las políticas de desarrollo profesional. Hay puntos importantes en lo documento que pueden contribuir a la organización del campo de la educación, especialmente en el área de Educación Física. Sin embargo, es muy importante entender la práctica profesional como productor de conocimiento, perspectiva que va más allá de los límites y reglas elaboración de directrices del plan de estudios, vinculado al contenido subyacente de las prácticas corporales.

Palabras clave: Educación Física; formación; Curriculum; Enseñanza; Profesionalización

Recebido em: junho/2016

Aprovado em: agosto/2016 